\title{
Life style modification in the management of hypertension in a sample of hypertensive patients attending Primary Health Care centers at Baghdad city
}

Maral F Thabit *, Samir K Al-Janabi **

\section{ABSTRACT}

Background: Modifications of life style are often critically important to adequately control excising hypertension.

Objective: :to determine the source of information regarding hypertension and lifestyle modification practices in the management of hypertension in a sample of Iraqi hypertensive patients.

Type of the study: Across-sectional study.:

Methods: The study was conducted over a period of two months during November and December 2015 at Primary Health Care center of Baghdad Al-GidedaAwaland Bab Al Mudhum primary health care centers. The sample included 219 hypertensive patients (102 females and 117males). They were subjected to a structured questionnaire consist of socio-demographic characteristics, duration of disease and source of information and different questions related to life style modification practices in the management of hypertension, also all participants were subjected to height and weight and blood pressure measurement. Data analysis by using SPSS programme vertion18.Frequeny, percentage for each question responses was calculated andpercent score was measured .

Results:The main source of information regarding lifestyle modifications was the health workers $(37.8 \%)$. The included patients were in the $5^{\text {th }}$ decade, mean duration of disease was $5.55 \pm 5.12 y e a r$, with mean systolic/diastolic blood pressure $142.6 / 89.3 \mathrm{mmHg}$, obese with mean BMI $32.14 \pm 5.19 \mathrm{~kg} / \mathrm{m}^{2}$.The dietary and drug intakelifestyle modification practices of patients were with higherpercent score $(90 \%, 88 \%$ and $84 \%)$ regarding decrease alcohol intake ,intake of healthy oils,stop smoking and intake of fresh fruits and vegetablesrespectively while the lower percent score $56 \%$ for intake of folic acid .

Conclusions: The lifestyle modification practices regarding body fitness was highest $82 \%$ for enough rest while for regular physical exercise was $68 \%$.

Key wards: life style modification,hypertensive patient, Baghdad.

\section{Al-Kindy College Medical Journal 2018: Vol. 14 No.1 Page: 13-17}
- $\operatorname{professor}(\mathrm{FICMS} / \mathrm{FM}) /$ Institute of Medical Technology/Baghdad
- assistant lecturer( DOM)/Institute of Medical Technology/Baghdad.

Received 20 $0^{\text {th }}$ Oct 2016, accepted in final $31^{\text {th }}$ Jan 2017 Corresponding to : Maral F Thabit, email: maral.fthabit@yahoo.com.
$\mathrm{H}$ ypertension or high blood pressure is known as the silent killer because it insidiously affects the body and leads to disability and premature death from stroke, heartdisease, heart failure and kidney failure $^{(1)}$. The prevalence of hypertensionvaries among countries and among subpopulations within a country. It has been estimated that hypertension accounts for $6 \%$ of deaths world-wide. In industrialized societies, blood pressure increases steadily during the first two decades ${ }^{(2)}$.Hypertension is a modern days epidemic and it is becoming a public emergency world-wide, especially in the developing countries ${ }^{(3,4)}$ and it is predicted by 2025 , the number of adults with hypertension will increase to1.56 billion ${ }^{(5)}$.Most of this increase is due epidemiological transition, recent changes in diet and social environment resembling that of developed societies $^{(6)} \cdot$ In developing countries, life style related chronic disease nearly burden the health related system $\left({ }^{7)} \cdot\right.$ Hypertension is considered the most common disease prevalent world-wide and according to the Iraqi national survey of non-communicable disease risk factor, $40.4 \%$ of Iraqi population are hypertensive ${ }^{(8)}$ A vast epidemiological study describes an apparent association between hypertension and life style choices $^{(9)}$. Life style factors such as weight reduction, physical activity and reduction in salt and alcohol intake have long been regarded as a means to prevent and control the occurrence of elevated blood pressure ${ }^{(10)}$ Modifications of life style are even more important to a much larger population of patients, those who are genetically predisposed to develop hypertension if exposed to adverse environmental factors (11). Adopting life style modification components not only reduces blood pressure but can delay the incidence of hypertension, enhance antihypertensive drug efficacy, and decrease cardio-vascular risk independent of changes in blood pressure readings ${ }^{(12)}$. Life style modification is indicated for all patients, withhypertension regardless of drug therapy, because it may reduce or even abolish the need for antihypertensive drugs $(13,14)$. Aims of the study:to determine the main source of information regarding hypertension among the studied sample and to determine lifestyle modification in the management of hypertensionin a sample of Iraqi patientsattending twoprimary health care centers,Baghdad.

Methods: A cross-sectional study by convenient sampling was conducted over a period of two months during October and November 2015 at the Primary 
Health care centers of Baghdad Al GididaAwal and Bab Al Mudham. The sample included 219 hypertensive patients (102females and 117males) with more than 1 year duration of disease with or without concurrent disease who were participated in the study after clarifying the purpose of the study and assuring high confidentiality and having verbal conscents. Illiterates,diabetics, pregnants sand mentally handicapped patients were not taken into account. All willing participants were subjected to a structured close ended questionnaire that consist of sociodemographic characteristics, duration of disease and source of information and different questions related to life style modification practices in the management of hypertension, also all participants were subjected to height and weight measurementsand body mass index was calculated by using Quetlet Index. $\left({ }^{15)}\right.$ Body mass index=weight $(\mathrm{kg}) /$ height $^{2}$ and then classified according to recommended cut-off points in to normal (18.5-24.9), overweight (25-29.9), obese(30-39.9). Blood pressure measurement also was done by using properly calibrated sphygmomanometer. Data analysis by using SPSS programme vertion18.Frequeny, percentage for each question responseswerecalculated. Each question was scored as 3 for always answer, 2 for answering as sometimes and 1 for never answer and percent score was measured using the following formula: Total score for all participants in the same item where total scores for all participants in the item $=$ never $x 1+2 x$ no of $I$ sometimes + no of always $x 3$ divided by the maximum possible score for all participants in the same item $=$ no of total mothers $x 3$ based on Triple likert score ${ }^{(16)}$ Results; Table (1) shows that the studied sample included 219 hypertensive patients as 117 (53.4\%) males , 102 (46.6\%) females . 80 (36.5\%) with no occupation , 49(22.3\%) with governmental jobs , 127 (58\%) were married , $85(39 \%)$ had more than secondary level education , only $52(24 \%)$ were smokers while the majority $212(96.8 \%)$ were not alcoholic , nearly half of the cases $108(49.3 \%)$ had family history of hypertension and $123(56 \%)$ had previous hospitalization due to hypertension. Table 2 shows that the source of information regarding hypertension was highest $83(37.8 \%)$ for health workers followed by 73(33.4) for relatives. Table 3 shows that the disease related variables for the studied patients were in the $5^{\text {th }}$ decade, mean duration of disease $5.55 \pm 5$.12year, uncontrolled B.P with mean systolic/diastolic pressure $142.6 / 89.33 \mathrm{~mm} \mathrm{Hg}$, obese with mean BMl 32.14 \pm 5.19 $\mathrm{kg} / \mathrm{m}^{2}$ Table 4 shows the dietary and drug intake changes for the included patients, the highest proportion of patients that always decrease alcohol intake , intake of unsaturated oils and stop smoking $(82 \%, 68.5 \%, 67 \%)$ with percent score $(90 \%, 88 \%, 84 \%)$ respectively while the lowest proportion for always intake of folic acid, excessive intake of onion and garlic , decrease tea and coffee $(14.3 \%, 24.2 \%, 27 \%)$ with percent score $(56 \%, 66 \%, 71 \%)$ respectively Table 5 shows life style changes related to body fitness and to have enough rest of the included patients with highly always proportion for enough rest, weight balance for normal body weight patient $(51.5 \%, 47.5)$ with percent score $82 \%, 78 \%$ respectively while the lowest proportion $(27.3 \%, 43-3 \%)$ with percent score $(68 \%$ and $75 \%)$ for regular physical exercise and decrease weight for obese and over - weight patients

Table (1): Distribution of the studied sample regarding socio-demographic characteristics. $(\mathrm{N}=219)$

\begin{tabular}{|c|c|c|}
\hline Socio-demographic characteristics & No & \% \\
\hline Gender & & 43.4 \\
\hline Male & 117 & \\
\hline Occupale & 102 & 22.3 \\
\hline Governmental jobs & & 21 \\
\hline Non-Governmental jobs & 49 & 13.2 \\
\hline Retired & 46 & 36.5 \\
\hline No job & 29 & 7 \\
\hline Daily payment Jobs & 80 & 58 \\
\hline Marital status & 15 & 28 \\
\hline Married & & 10 \\
\hline Single & 127 & 4 \\
\hline Widow & 61 & 22 \\
\hline Separated / divorced & 9 & 18.7 \\
\hline Educational level & & 20 \\
\hline Read and write & 41 & 22.3 \\
\hline Primary education & 44 & 39 \\
\hline Secondary education & 49 & \\
\hline Smoking history & 85 & \\
\hline
\end{tabular}




\begin{tabular}{|c|c|c|}
\hline Current smoker & 52 & 24 \\
\hline Not smoker & 139 & 63 \\
\hline Ex-smoker & 28 & 13 \\
\hline Alcohol intake & & \\
\hline Yes & 7 & 3.2 \\
\hline No & 212 & 96.8 \\
\hline Family history of Hyper tension & & 49.3 \\
\hline Yes & 108 & 50.7 \\
\hline No & 111 & 56 \\
\hline Previous hospitalization Due to hypertension & & 44 \\
\hline Yes & 123 & \\
\hline No & 96 & \\
\hline
\end{tabular}

Table 2 : The distribution of the studied sample according to the source of information $(\mathrm{N}=219)$.

\begin{tabular}{|r|r|r|}
\hline Source information & N & \% \\
\hline Friends & 40 & 18.3 \\
\hline Relatives & 73 & 33.4 \\
\hline TV/Radio/lnternet & 17 & 7.8 \\
\hline Journals and Magazines & 6 & 2.7 \\
\hline Health workers & 83 & 37.8 \\
\hline
\end{tabular}

Table 3 Distribution of the studied sample regarding the mean \pm SD of continuous variables.

\begin{tabular}{|c|c|}
\hline Variable & Mean \pm SD \\
\hline Mean age of males (year) & $59.31 \pm 13.87$ \\
\hline Mean age of females (year) & $51 \pm 10.34$ \\
\hline Mean duration of disease $($ year) & $5.55 \pm 5.12$ \\
\hline Mean systolic blood pressure $(\mathrm{mm} \mathrm{Hg})$ & $142.6 \pm 15.69$ \\
\hline Mean diastolic blood pressure $(\mathrm{mm} \mathrm{Hg})$ & $.33 \pm 10.66$ \\
\hline Mean body mass index $\left(\mathrm{kg} / \mathrm{m}^{2}\right)$ & $32.14 \pm 5.19$ \\
\hline
\end{tabular}

Table 4: Dietary and drug intake life style modification of the studied hypertensive patients $(\mathrm{N}=219)$.

\begin{tabular}{|c|c|c|c|c|c|c|c|}
\hline \multirow[t]{2}{*}{ Dietary and drug intake changes } & \multicolumn{2}{|c|}{ Always } & \multicolumn{2}{|c|}{ Sometimes } & \multicolumn{2}{|c|}{ Never } & \multirow{2}{*}{$\begin{array}{l}\text { Percent } \\
\text { score }\end{array}$} \\
\hline & no & $\%$ & no & $\%$ & no & $\%$ & \\
\hline Decrease salt intake & 98 & 45 & 107 & 49 & 14 & 6 & 79 \\
\hline Decrease tea and coffee intake & 60 & 27 & 125 & 57 & 34 & 16 & 71 \\
\hline Excessive intake of onion and garlic & 53 & 24.2 & 108 & 49.3 & 58 & 26.5 & 66 \\
\hline Intake of un saturated oils in & 150 & 68.5 & 59 & 27 & 10 & 4.5 & 88 \\
\hline Increase fluid intake & 103 & 47 & 109 & 50 & 7 & 3 & 81 \\
\hline Increase intake fiber diet & 63 & 28.7 & 142 & 65 & 14 & 6.3 & 74 \\
\hline $\begin{array}{l}\text { Increase intake of fresh fruits and } \\
\text { vegetables }\end{array}$ & 118 & 54 & 98 & 44.7 & 3 & 1.3 & 84 \\
\hline Decrease alcohol intake & 180 & 82 & 13 & 6 & 26 & 12 & 90 \\
\hline Stop smoking & 196 & 67 & 72 & 19 & 31 & 14 & 84 \\
\hline $\begin{array}{l}\text { Intake of folic acid and preventive } \\
\text { measure }\end{array}$ & 31 & 14.3 & 86 & 39.2 & 102 & 46.5 & 56 \\
\hline Stop intake of NSAID & 80 & 36.5 & 112 & 51.2 & 27 & 12.3 & 74 \\
\hline
\end{tabular}

Table 5: Life style change related to body fitness and enough rest $(\mathrm{N}=\mathbf{2 1 9})$

\begin{tabular}{|c|c|c|c|c|c|c|c|}
\hline Body fitness changes & \multicolumn{2}{|c|}{ Always } & \multicolumn{2}{|c|}{ Some times } & \multicolumn{2}{|c|}{ Never } & Percent \\
\hline $\begin{array}{r}\text { Decrease weight for obese and over - } \\
\text { weight patients }\end{array}$ & 95 & 43.3 & 84 & 38.3 & 40 & 18.4 & 75 \\
\hline Weight balance for normal body weight & 104 & 47.5 & 88 & 40.2 & 27 & 12.3 & 78 \\
\hline
\end{tabular}




\begin{tabular}{|c|c|c|c|c|c|c|c|}
\hline patients & & & & & & & \\
\hline Enough rest & 113 & 51.5 & 93 & 42.5 & 13 & 6 & 82 \\
\hline Regular physical exercise $15-30 \mathrm{~min} /$ day & 60 & 27.3 & 108 & 49.4 & 51 & 23.3 & 68 \\
\hline
\end{tabular}

Discussion: The role of lifestyle modifications as both preventive and adjunctive means to lower blood pressure has been reaffirmed by manyinvestigations ${ }^{(17,}$ ${ }^{18.19)}$. Life style modifications to introduce healthy behaviors are important in the primary prevention of high blood pressure, and are on imperative part of the management of the patient with established hypertension. ${ }^{(20)}$ The main source of information regarding lifestyle modification practices in the present study was the health workers of in about one third patients $37.8 \%$, while more than $50 \%$ of the respondents of Ike So etal knew about the life style measures through health personnel and adopted these measures once they became aware of their effects. . ${ }^{(21)}$ The included hypertensive patients had uncontrolled hypertension with mean BP 142.6/89.3 mmHg,this finding in agreement with Aubert $\mathrm{L}$ etal ${ }^{(6)}$ respondents with mean $\mathrm{BP}(153 / 98) \mathrm{mmHg}$. Trial to stop smoking was practiced by more than half of patients $67 \%$ while the findings of Zungo and Djumbe ${ }^{(22)}$ revealed that in $96 \%$ gave correct responses for practices related to prohibiting or preventing smoking. Although garlic and its preparations have been widely recognized as agents for prevention and treatment of cardio-vascular and other metabolic disease ${ }^{(23)}$ yet it was always practiced by $24.2 \%$ of the patients.More than half of the respondents $54 \%$ increased fresh fruits and vegetables consumption in comparison only $21.3 \%$ regularly took plenty of vegetables and $22.2 \%$ took plenty of fruits by ${ }^{(23)}$ respondents. GuddadS etal ${ }^{(24)}$ in his study revealed that $78 \%$ of patients were consuming vegetarian diet ,this due that it contains less cholesterol and saturated fats. Nearly two thirds of respondents $68.5 \%$ preferred using healthy oil in cooking and $45 \%$ decrease salt intake. The result of Ashfaq $\mathrm{T}$ et al at Karachi revealed that $91 \%$ used oil for cooking ${ }^{(25)}$ also results of Ozdemir $\mathrm{L}$ and Sumer $\mathrm{RH}^{(26)}$ revealed that $51.9 \%$ preferred poly unsaturated fats as dietary habits,32.8\% had high density salt intake while $81.5 \%$ of suburban Nigerian community took much table salt but $18.5 \%$ did not ${ }^{(21)}$. Salt intake was restricted by $34.7 \%$ while $20 \%$ avoided it. ${ }^{(27)}$ alsoRao and Easwaron found that hypertensive patients consumed salty foods like pickle apad and bakery items less frequently. ${ }^{(28)}$ Although physical activity is a primary lifestyle measure required to lower blood pressure in hypertensive patients. ${ }^{(1)}$ Yet it was practiced always by $27.3 \%$ of the included patients ,while only $9.3 \%$ of suburban Nigerian community did regular exercise $^{(21)}$. While Ozdemir $L$ and Sumer $\mathrm{RH}$ found that $91 \%$ of the cases had moderate level of physical activity. ${ }^{(26)}$ also $35 \%$ of patients of Tbblin $G$ and Aberg $H$ ) ${ }^{(27)}$ responders increased their physical activity. Exercise in the form of walking was practiced also by $63 \%$ of the patients. ${ }^{(24)}$
Conclusions: The main source of information regarding hypertension among the studied sample was health workers.

- The highest proportion of always dietary intake modification practices were for decrease alcohol intake, consume unsaturated oils and stop smoking.

- $\quad$ Sleeping enough time was the main practice while physical exercise was the less practice among the life style modification practices.

\section{Recommendations:}

1-There is a need for good hypertension education programs at the primary care level with emphasis on motivating poor life style modifications.

2- A well organized and structured education counseling programme should be established as quickly as possible for hypertensive patients about all aspects of hypertension.

3-Confirmation of the findings on larger multicenter population residing at Baghdad and other different Iraqi governorates

\section{References:}

1- ALLAT Officers and Cordinators for the ALLAT Collaborative Research Group.Major outcomes in high risk hypertensive patients randomized into angiotensin converting enzyme inhibitor or calicium channel blockers vs diuretics.JAMA,2002,288:29812997.

2- Fauci HKB,LongolJ.Principles of Internal Medicine,seventeenth edition,2008.

3- Kearny PM, WheltonM, Reynold K, WheltonPK,HeJ.Worldwide prevalence of hypertention: asystetematicreview. Hypertention 2004,22(1):21-24.-7330.

4 P.HeJ.ChenJ,RoccellaFJ.StreiffetesrRH.WheltonPK.F actors associated with hypertention control in the general population of he United tyState.Arch Internal Med 2002:162-ens051-1055

5- Carretero OA.OpriiS.Essentialhypertention.part 1: definition and etiology. Circulation ,2000,101:329335

6- Aubert $L$ ertal.knowledge,attitudes and practices on hypertention in a country in epidemiological transition.Am Heart Assoc 1998:1136-1145. 
7- Molunine M,WikasK,Karishwor A.A study of the effect of lifestyle factors on the prevalence of hypertention among white collar job people of S-urat.Thelntenet journal of occupational Health ${ }^{\mathrm{TM}}$ issn.215-7330.

8- Iraqi National Survey of non communicabledisease, risk factor. (2006)

9- Walker J,MacknzieAD, DunningJ.Does reducing your salt intake make you live longer?.InternetCardiovarcizescular Thoracic Surgery 2007:6(6):793-8.

10-Braith RW,StewartKJ.Resistaionceexecizetraining:its role in the prevention of cardio-vascular diseae.Circulation 2006:113(22):2642-50

11-Norman M,aKaplanMiontD.Life-style modifications for prevention and treatment of hypertention. The journal of clinical hypertension 2004,1(12)

12M,SvetkeyIP,VollinerWM,AppellJ,dtBrayGA,Harshare Dionetal.Effects on blood pressure of reduced dietary sodium and the dietadry approaches to stop hypertention (DASH) DASH-Sodium Collaborative Research Group..NEnol j Med 2001, 4,344(1):3-10

13-Godfrey BS,Lyalomhel and Sarah I,IYalomhe 2e.Hypertention related knowleudedge, attitudes and life style practices among hypertensive patients in Sub-urban Nigerian Community j of public health and Epidemiology.2010,2(4):71-77

14-Ineke NeutelC,Campbell NRC changes in life style after hypertention in Canada.Cardiology,2008,24(3):199-204.

15- Mansour AA. and Al-Jazairi MI. Cut-offValues for Anthropometric variables That Conferlncreased Risk of Type 2 Diabetes Mellitus andHypertension in Iraq. Arch. Med. Res. (2007). 38(2): 253-258.

16- Harry N. Boone JR, Deborah A. Boone.Analyzsinglikert at data. Journal of Extention, 2012, vol.50, no2., Tools of the Trade,2TOT2.

17-Appel LJ,ChampagreCM,HarshaDWetal.Effects of comprehensive life style modification on blood pressure control.JAMA,2003,289:2083-93.
18-Colin PR.Dietary modification and changes in blood pressure.CurrOpinnNephrolHypertens 2001:10:35962.

19-Cakir H,PinarR.Randomized controlled trial on life style modification on hypertensive patients. West $\mathrm{j}$ Nurs Res,2006,vol:28,190-209.

20-Derman EW,WhitesmansS.Life style modifications for the prevention of hypertention:A clinical and costeffective Review.2008.

21-Ike SO,Aniebue PN and AniebueUU.knowledge,perceptions and practices of life style modification measures among adult hypertensives in Nigeria.Oxfordjournals. Transactions of the Royal Society of Tropical Medicine and Hygiene,2009.vol:104.issue:1,55-

22-Zungo Li,DjumbeFR.Knowledge and life style practices of hypertensive patients attending a primary health clinic in Botswana.2004,1(12).

23-Banerjee SK and MaulikS.Effect of garlic on cardiovascular disorders:areview.Nutrition J,2002,1,4.

24-Guddad S,MsabialagiU,Kasturiba and Hasabil.Knowledge and life style factors of hypertensive subjects.Karnataka j Agric.SCI,2012,25(3):373-376.

25-Ashfaq T,AnjumQ,SiddiquiH,ShAIKHF.Awareness of hypertention among patients attending primary health care center.JPMA,,2007,57(8):396-9.

26-Ozdemir L,Sumer $\mathrm{H}$ :The effect of educational intervention on bloob pressure levels e among hypertensive female patients aged above 30 and living in Sirat.Cumburiyet Medical journal.2009,31:31-40.

27-Tibblin $G$ and ABERG h.Non pharmacological treatment of hypertensive differences Between health centers in patients blood pressure and success at withdrawal from drugs:Family practice journal,1999,vol:7,issue:1.47-51.

28-Rao UM and EswaranP.Impact of high potassium intake of selected hypertensive patients.Indian J Nut.Dietet, 1990,27:67-76. 